\title{
Strong motions observed by K-NET and KiK-net during the 2016 Kumamoto earthquake sequence
}

\author{
Wataru Suzuki* ${ }^{*}$, Shin Aoi, Takashi Kunugi, Hisahiko Kubo, Nobuyuki Morikawa, Hiromitsu Nakamura, \\ Takeshi Kimura and Hiroyuki Fujiwara
}

\begin{abstract}
The nationwide strong-motion seismograph network of K-NET and KiK-net in Japan successfully recorded the strong ground motions of the 2016 Kumamoto earthquake sequence, which show the several notable characteristics. For the first large earthquake with a JMA magnitude of 6.5 (21:26, April 14, 2016, JST), the large strong motions are concentrated near the epicenter and the strong-motion attenuations are well predicted by the empirical relation for crustal earthquakes with a moment magnitude of 6.1. For the largest earthquake of the sequence with a JMA magnitude of $7.3(01: 25$, April 16, 2016, JST), the large peak ground accelerations and velocities extend from the epicentral area to the northeast direction. The attenuation feature of peak ground accelerations generally follows the empirical relation, whereas that for velocities deviates from the empirical relation for stations with the epicentral distance of greater than $200 \mathrm{~km}$, which can be attributed to the large Love wave having a dominant period around $10 \mathrm{~s}$. The large accelerations were observed at stations even in Oita region, more than $70 \mathrm{~km}$ northeast from the epicenter. They are attributed to the local induced earthquake in Oita region, whose moment magnitude is estimated to be 5.5 by matching the amplitudes of the corresponding phases with the empirical attenuation relation. The real-time strong-motion observation has a potential for contributing to the mitigation of the ongoing earthquake disasters. We test a methodology to forecast the regions to be exposed to the large shaking in real time, which has been developed based on the fact that the neighboring stations are already shaken, for the largest event of the Kumamoto earthquakes, and demonstrate that it is simple but effective to quickly make warning. We also shows that the interpolation of the strong motions in real time is feasible, which will be utilized for the real-time forecast of ground motions based on the observed shakings.
\end{abstract}

Keywords: 2016 Kumamoto earthquake, Strong motion, PGA, PGV, Attenuation relation, Record section, Induced earthquake, Earthquake early warning, Real-time interpolation

\section{Background}

The 2016 Kumamoto earthquake sequence rocked central Kyushu around Kumamoto prefecture, Japan, starting with the first earthquake having $M_{\mathrm{JMA}} 6.5$ (magnitude determined by Japan Meteorological Agency: JMA) at 21:26 on April 14, 2016 (JST = UTC + 9), which we call M6.5 event in this paper. The largest event of the sequence occurred at 1:25 on April 16, 2016 (JST), with

\footnotetext{
*Correspondence: wsuzuki@bosai.go.jp

National Research Institute for Earth Science and Disaster Resilience, 3-1 Tennodai, Tsukuba, Ibaraki 305-0006, Japan
}

$M_{\text {IMA }} 7.3$ (hereafter $M 7.3$ event) having an epicenter close to M6.5 event. These two large events caused the severe shakings up to the maximum seismic intensity of 7, the largest intensity on the JMA scale, to the near-source area along the Futagawa and Hinagu fault zones, where a potential of $M 7$-class earthquake had been recognized by the long-term evaluation and the JMA seismic intensity of 6-upper had been estimated from the seismic hazard assessment (Headquarter for Earthquake Research Promotion 2013). The repeated severe shakings resulted in a lot of loss of lives and damage on the houses and buildings; death toll including disaster-related death is 178 and 
the number of totally collapsed houses amounts to more than 8300, according to Fire and Disaster Management Agency (2016).

For the mitigation of earthquake disaster, it is highly important to reliably record the strong motions even in the severe condition and transfer the recorded data immediately to the data management center and to the users in order to effectively respond to the ongoing earthquake disasters as well as to investigate the nature of destructive strong motions and to advance the evaluation of the seismic hazard and risk. National Research Institute for Earth Science and Disaster Resilience (NIED) has constructed and maintained the two nationwide strongmotion seismograph networks K-NET (Kyoshin network) and KiK-net (Kiban-Kyoshin network) (Kinoshita 1998; Okada et al. 2004; Fujiwara et al. 2007; Kunugi et al. 2009; Aoi et al. 2011). As a dense strong-motion network in which stations are deployed at approximately $20-\mathrm{km}$ interval, K-NET and KiK-net have succeeded in obtaining a large amount of strong-motion data including the near-source area of the Kumamoto earthquake sequence. These data will contribute not only to reinforcement of the earthquake disaster resilience but also to advancement of revealing the nature of earthquakes as they contain much information about earthquake sources (e.g., Fukuyama and Suzuki 2016; Kubo et al. 2016).

In this paper, we present the characteristics of strong motions obtained by K-NET and KiK-net particularly for $M 6.5$ and M7.3 events starting with the spatial distribution of peak ground acceleration (PGA) and peak ground velocity (PGV). The distribution of these peak values suggests some notable characteristics specific to the Kumamoto earthquakes, and the factors causing them are then investigated. These analyses are relatively conventional approaches to exploiting the information after the earthquake based on the stably recorded triggered data. The real-time observation of strong motions has become feasible, which will contribute to ongoing earthquake disaster mitigation. To demonstrate its potential, we finally present our efforts to utilize the real-time strong-motion observations for rapidly and certainly issuing a warning of strong shakings.

\section{K-NET and KiK-net strong-motion data opened to the public}

Until July 29, 2016, NIED has opened 19,211 strongmotion records obtained by K-NET and KiK-net due to 432 events of the 2016 Kumamoto earthquake sequence through the Internet (http://www.kyoshin.bosai.go.jp/). These data are triggered data which are recorded once the acceleration exceeds the level predetermined for each station. The data file is created from $15 \mathrm{~s}$ before the trigger time (pre-trigger portion) and ends when the acceleration level becomes lower than the criterion value or duration reaches $300 \mathrm{~s}$ (5 min). NIED opens the strong-motion data for latest earthquakes for which the maximum JMA seismic intensity of 3 or greater is observed and reported by the JMA. The strong-motion data of earthquakes with the maximum JMA seismic intensity of 2 are usually added to the Web site in the next month. During the 2016 Kumamoto earthquake sequence, K-NET and KiK-net observed the maximum JMA seismic intensity of 7 for M7.3 event, 6-upper for M6.5 event, and 6-lower for three events. In the following sections, we describe the characteristics of the observed strong motions by K-NET and KiK-net for the two particularly large earthquakes, i.e., $M 6.5$ and $M 7.3$ events.

\section{Strong motions of $\mathbf{M} \mathbf{6 . 5}$ event}

For M6.5 event, the first large event of the sequence, K-NET obtained strong-motion acceleration data on surface at 191 stations and KiK-net recorded the data on surface and in the borehole at 146 stations. Figure 1 shows the spatial distribution of PGA and PGV observed by K-NET and KiK-net for M6.5 event. The PGA and PGV are calculated from the vector sum of the three components. A high-pass filtering with a corner period of $10 \mathrm{~s}$ is applied to velocity waveforms for PGV. The large PGAs of approximately 500 gals $(\mathrm{cm} /$ $\mathrm{s}^{2}$ ) or larger and large PGVs are observed in an area near the epicenter. PGA of 1580 gals, the largest value among K-NET and KiK-net stations, and seismic intensity of 6-upper were observed at KiK-net KMMH16 station (Mashiki) located just $6 \mathrm{~km}$ away from the epicenter. Figure 2 shows the attenuation of the observed PGA and PGV to the fault distance with the empirical relation for $M_{\mathrm{W}}$ (moment magnitude) 6.1 crustal earthquake proposed by Si and Midorikawa (1999). Here, the PGA and PGV are taken as a larger value between the two horizontal components and are band-pass filtered in order to adopt the same procedure of $\mathrm{Si}$ and Midorikawa (1999). The PGVs are corrected to be equivalent to the values at sites with $\mathrm{AVS}_{30}$ (average $S$-wave velocity in the upper $30 \mathrm{~m}$ ) of $600 \mathrm{~m} / \mathrm{s}$ using the relationship between the site amplification factor and $\mathrm{AVS}_{30}$ proposed by Midorikawa et al. (1994). The fault distance is calculated assuming a $10 \mathrm{~km} \times 10 \mathrm{~km}$ rectangular fault having a strike angle of $211^{\circ}$ and a dip angle of $87^{\circ} . M_{\mathrm{W}}$, strike, and dip angles are decided referring to the F-net moment tensor solution (NIED 2016). We can see that the empirical attenuation relation well follows the observed PGA and PGV of M6.5 event even for the near-source stations and also for the farther stations (hypocenter distance $>100 \mathrm{~km}$ ), for which the 


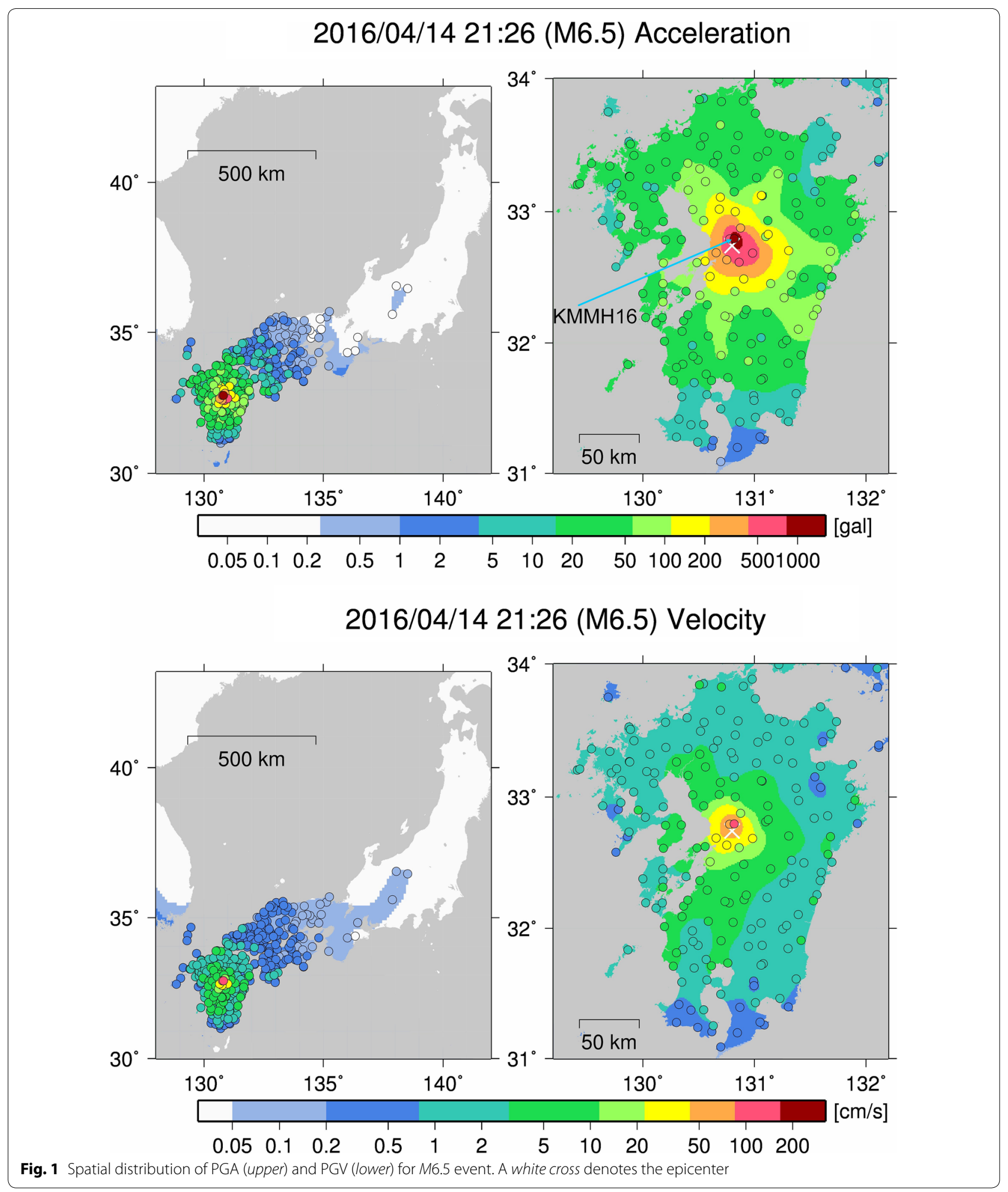

empirical relation for $M_{\mathrm{W}} 6.1$ earthquake is extrapolation, although the PGA and PGV of nearest station, KiKnet KMMH16, are larger than the empirical relation by approximately one standard deviation. Therefore, the strong motions due to M6.5 event are considered to be typical for earthquakes of such a magnitude. 

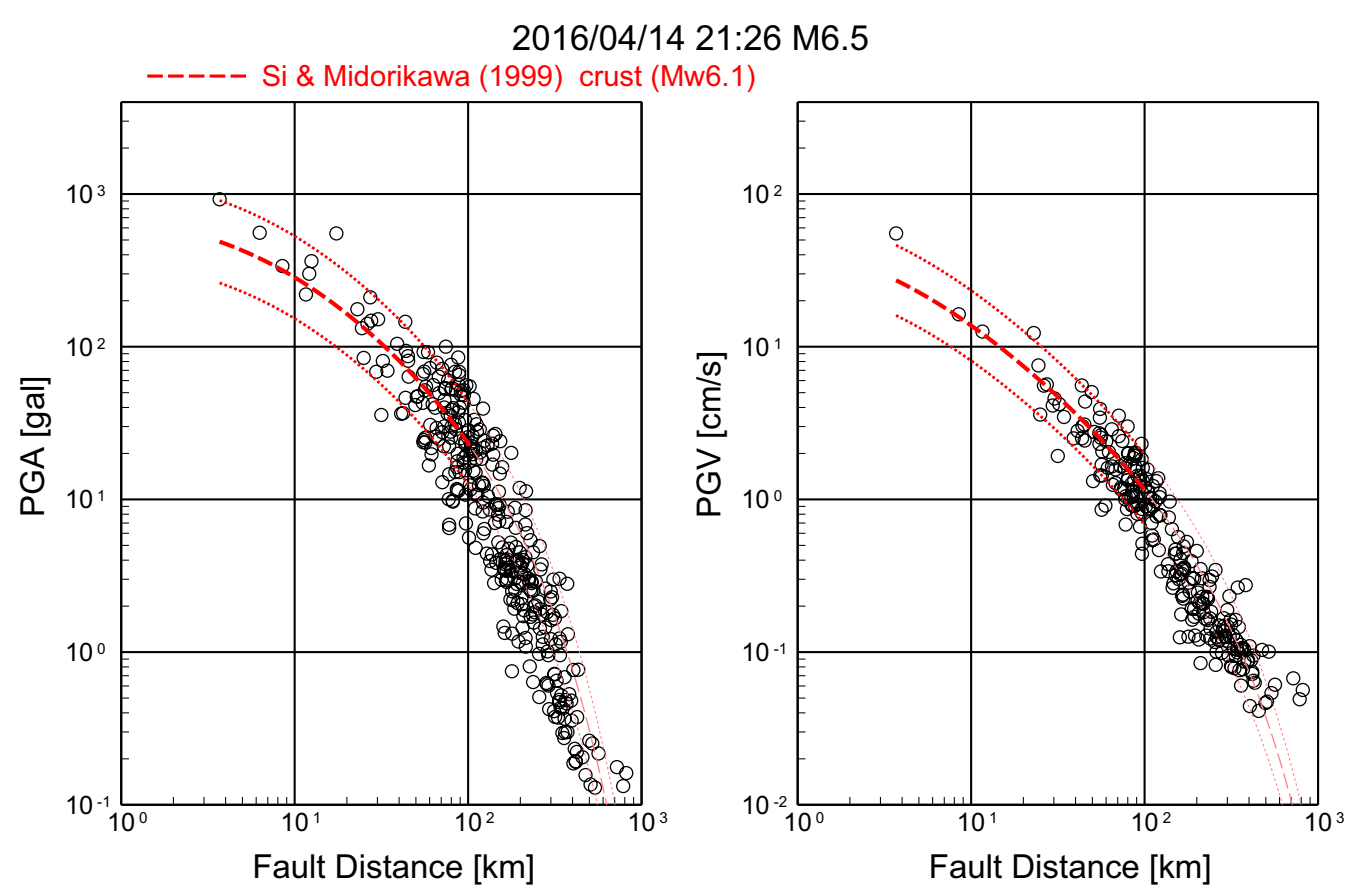

Fig. 2 Observed PGA (left) and PGV (right) attenuation to the fault distance of M6.5 event compared with the empirical relation proposed by Si and Midorikawa (1999) for $M_{w} 6.1$ crustal earthquake denoted by red dashed line. The red dotted lines denote the range of the standard deviation, and thin lines mean that the distances are larger than those used to derive the empirical relation

\section{Strong motions of $M 7.3$ event}

For M7.3 event, K-NET and KiK-net, respectively, obtained strong-motion data at 370 surface stations and at 328 stations on surface and in the borehole, and therefore recorded ground motions at, in total, 698 stations. Figure 3 shows the spatial distribution of the PGA and PGV observed by K-NET and KiK-net. The figure is produced following the same procedure as Fig. 1. Compared with Fig. 1, it is obvious in Fig. 3 that the area of the large PGA and PGV is wider, extending from the area around the hypocenter to the northeast direction. One reason for the extension of large shaking area to the northeast can be attributed to the source rupture process in which the main rupture propagated to the northeast (e.g., Kubo et al. 2016), and another reason can be the induced earthquake in Oita region around OIT009 and OITH11 stations addressed later in this paper. The largest PGA among K-NET and KiK-net is 1362 gals observed again at KiK-net KMMH16 station, located $7 \mathrm{~km}$ from the epicenter. JMA seismic intensity is calculated as 7 from the acceleration waveform of KiK-net KMMH16. Figure 4 shows the attenuation of observed PGA and PGV to the fault distance with the empirical relation of $M_{\mathrm{W}} 7.0$ crustal earthquake proposed by $\mathrm{Si}$ and Midorikawa (1999). The PGA and PGV are processed following the same procedure as $M 6.5$ event. The fault distance is calculated assuming a $30 \mathrm{~km} \times 14 \mathrm{~km}$ rectangular fault having a strike angle of $224^{\circ}$ and a dip angle of $88^{\circ}$, referring to the F-net moment tensor solution (NIED 2016). The observed PGAs are generally reproduced by the empirical attenuation relation within the standard deviation from the near-fault stations to the farther stations. Contrary, PGVs largely deviate from the empirical relation at stations whose fault distance is greater than $200 \mathrm{~km}$. Although this distance range is actually outside of that used to derive the empirical relation by $\mathrm{Si}$ and Midorikawa (1999), the deviation of the observed PGV is a characteristic specific to $M 7.3$ event since the empirical relation well models the strong motions outside of the used distance range for previous large earthquakes, e.g., the 2003 Tokachi-oki earthquake in Japan (Honda et al. 2004).

To see the cause of the large PGV, we plot record sections of velocity waveforms band-pass filtered between 5 and $20 \mathrm{~s}$ along the northeast direction in Fig. 5. In the transverse component, there is a notable phase with a long pulse width that has much larger amplitude than the empirical relation for the same fault distance and arrives later than the first $S$-wave train. The observed peak velocities for the transverse components are greater than 4.0 and $2.5 \mathrm{~cm} / \mathrm{s}$ at the stations 200 and $400 \mathrm{~km}$ away from the fault plane whereas the predicted values from the empirical relation are around 1.0 and $0.2 \mathrm{~cm} / \mathrm{s}$ for the corresponding stations. The radial and vertical components have a few phases that 


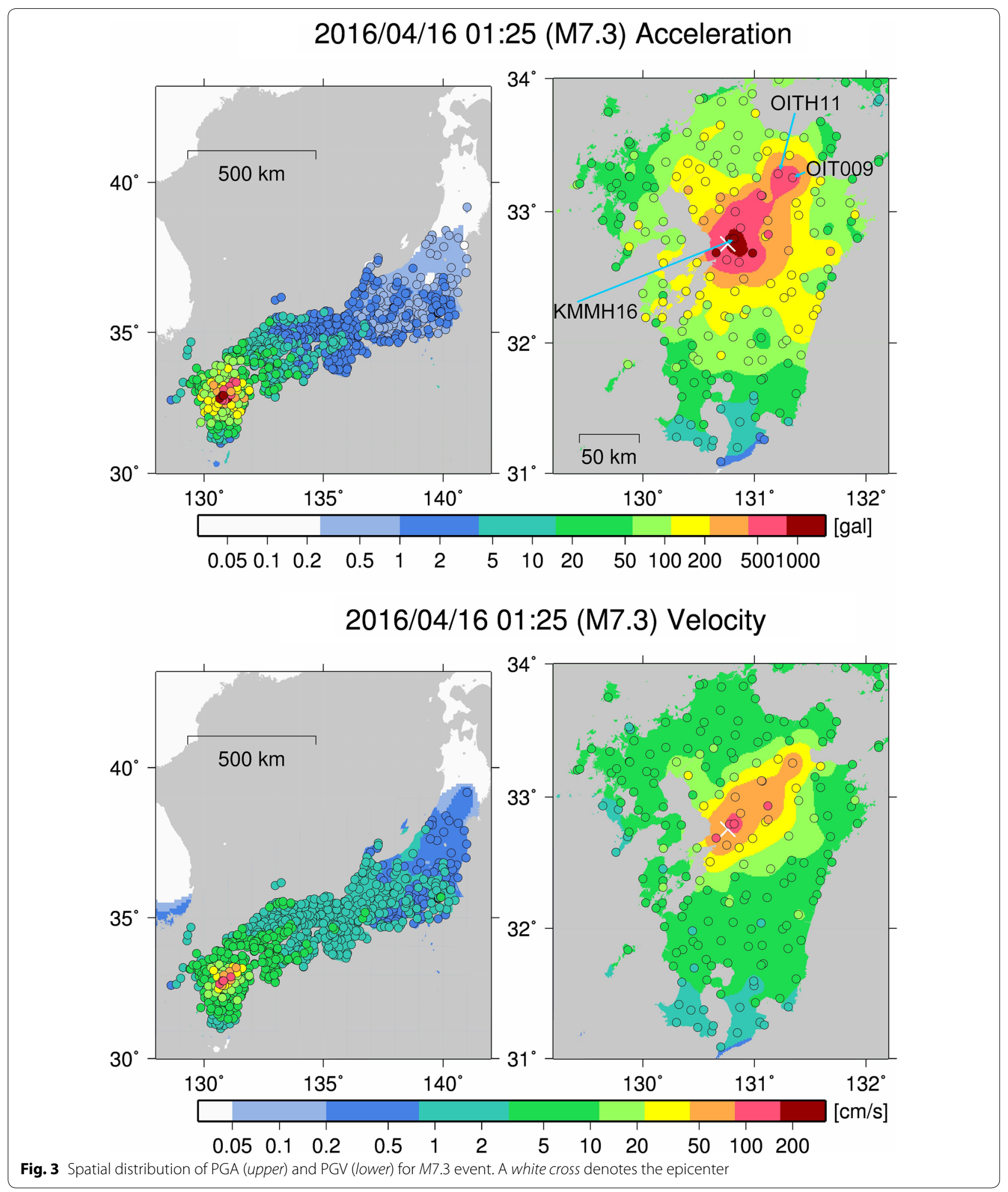

are synchronized with each other and have much smaller amplitudes than the phase in the transverse component. The dominant period of the large phases in the transverse component is around $10 \mathrm{~s}$. Furumura et al. (2003) shows that in western Japan the strong motions due to large earthquake are characterized by $L_{\mathrm{g}}$ waves dominated in 
2016/04/16 01:25 M7.3
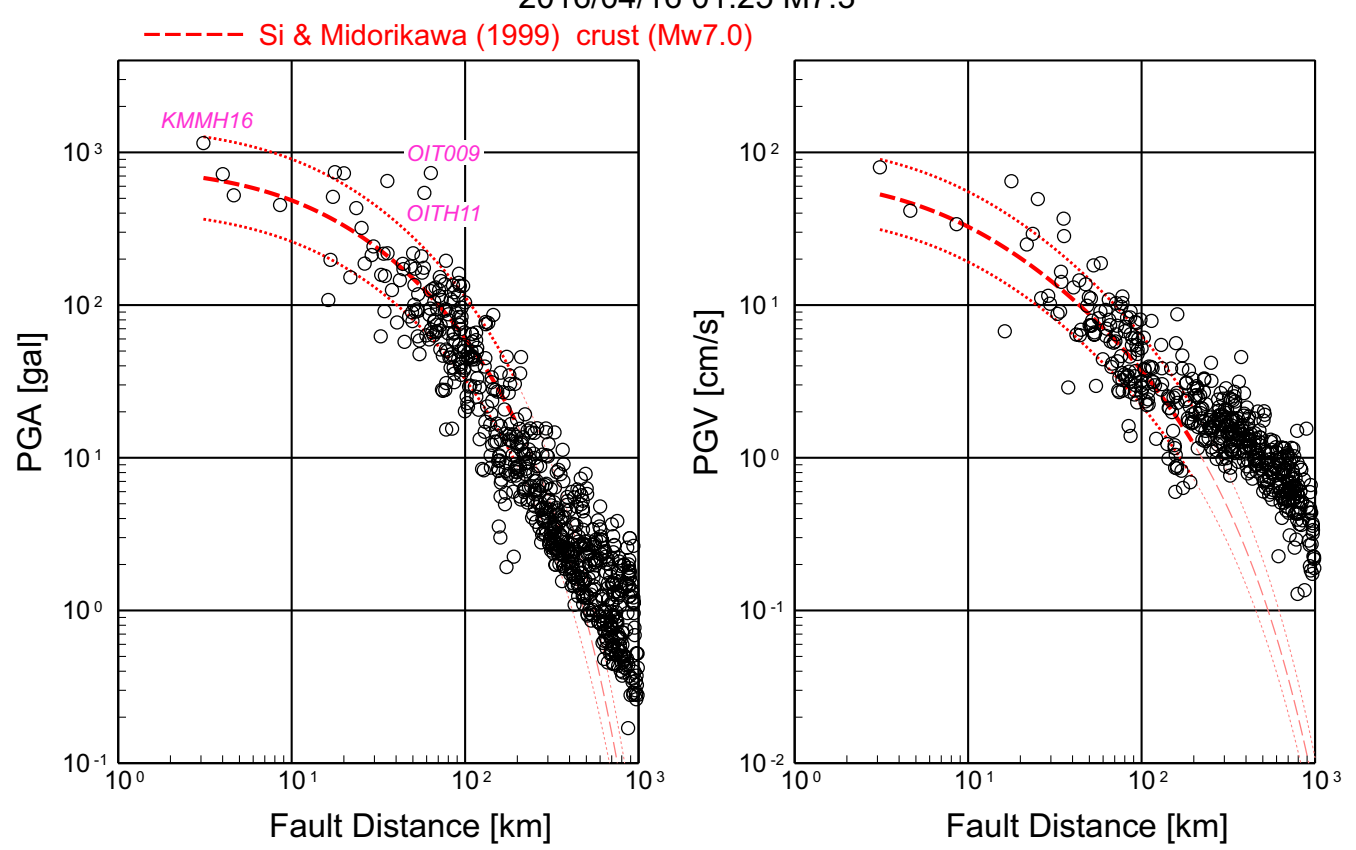

Fig. 4 Observed PGA (left) and PGV (right) attenuation to the fault distance of M7.3 event compared with the empirical relation proposed by Si and Midorikawa (1999) for $M_{W} 7.0$ crustal earthquake denoted by red dashed line. The red dotted lines denote the range of the standard deviation, and thin lines mean that the distances are larger than those used to derive the empirical relation

the short-period band $(0.2-5 \mathrm{~s})$ and longer-period $(\sim 10 \mathrm{~s})$ fundamental-mode Love waves from the observation and simulation of the 2000 western Tottori earthquake. As pointed by Dhakal et al. (2016), the stations aligned in Fig. 5 are located in the area where large-amplitude $\mathrm{SH}$ waves are expected from the source radiation pattern. The anomalously large amplitudes in this direction are not seen for M6.5 event in spite of a similar focal mechanism to $M 7.3$ event. According to Kubo et al. (2016), M7.3 event has large slips in the shallow region and a longer source duration (>16 s) than that of M6.5 event ( $6 \mathrm{~s}$ ). This suggests that the generation of the large-amplitude Love wave is strongly dependent on the fault rupture process. It is probable that long-period $\mathrm{SH}$ waves radiated to the northeastern direction due to a rupture having a long duration and shallow large slips developed into the large-amplitude Love waves, coupled with crustal structure of western Japan, which efficiently propagates Love wave with a period of approximately $10 \mathrm{~s}$. The large observed PGV deviated from the empirical relation for the farther stations from the source area can be attributed to thus generated Love waves propagating to the northeastern direction.

\section{Induced earthquake in Oita region due to $M 7.3$ event}

In PGA and PGV spatial distribution of Fig. 3, large values appear in Oita region, to the northeast and relatively far from the source area of $M 7.3$ event. Figure 6a shows the acceleration waveforms recorded at K-NET OIT009 and KiK-net OITH11 stations, which have epicentral distances larger than $70 \mathrm{~km}$ and recorded large PGA values over 500 gals. It can also be confirmed from Fig. 4 that these two stations have anomalously large PGA for fault distance around $50 \mathrm{~km}$. In Fig. 6a, the first $P$ and $S$ waves that propagate from the source area of $M 7.3$ event, which are indicated by blue arrows, do not have so large amplitudes: They are approximately 90 gals for OIT009 and 250 gals for OITH11 stations. These amplitudes are consistent with the PGA empirical attenuation relation. Approximately 20 and $10 \mathrm{~s}$ after the first $P$ - and $S$-wave arrivals when the $S$ waves from the source area decrease their amplitudes, the larger-amplitude phase appears in the waveforms at these two stations with the peak values of 723 gals and 698 gals for OIT009 and OITH11 stations, respectively. These large-amplitude phases are considered to be caused by a local earthquake in Oita region induced by M7.3 event as they first appeared at OIT009 and then arrived the other stations with an apparent velocity of approximately $3.5 \mathrm{~km} / \mathrm{s}$ as shown in record section of Fig. 6b.

The location and magnitude of the induced earthquake are estimated by fitting the PGA attenuation relation with the corresponding phases. We only use the peak value of the vector sum of the horizontal components 


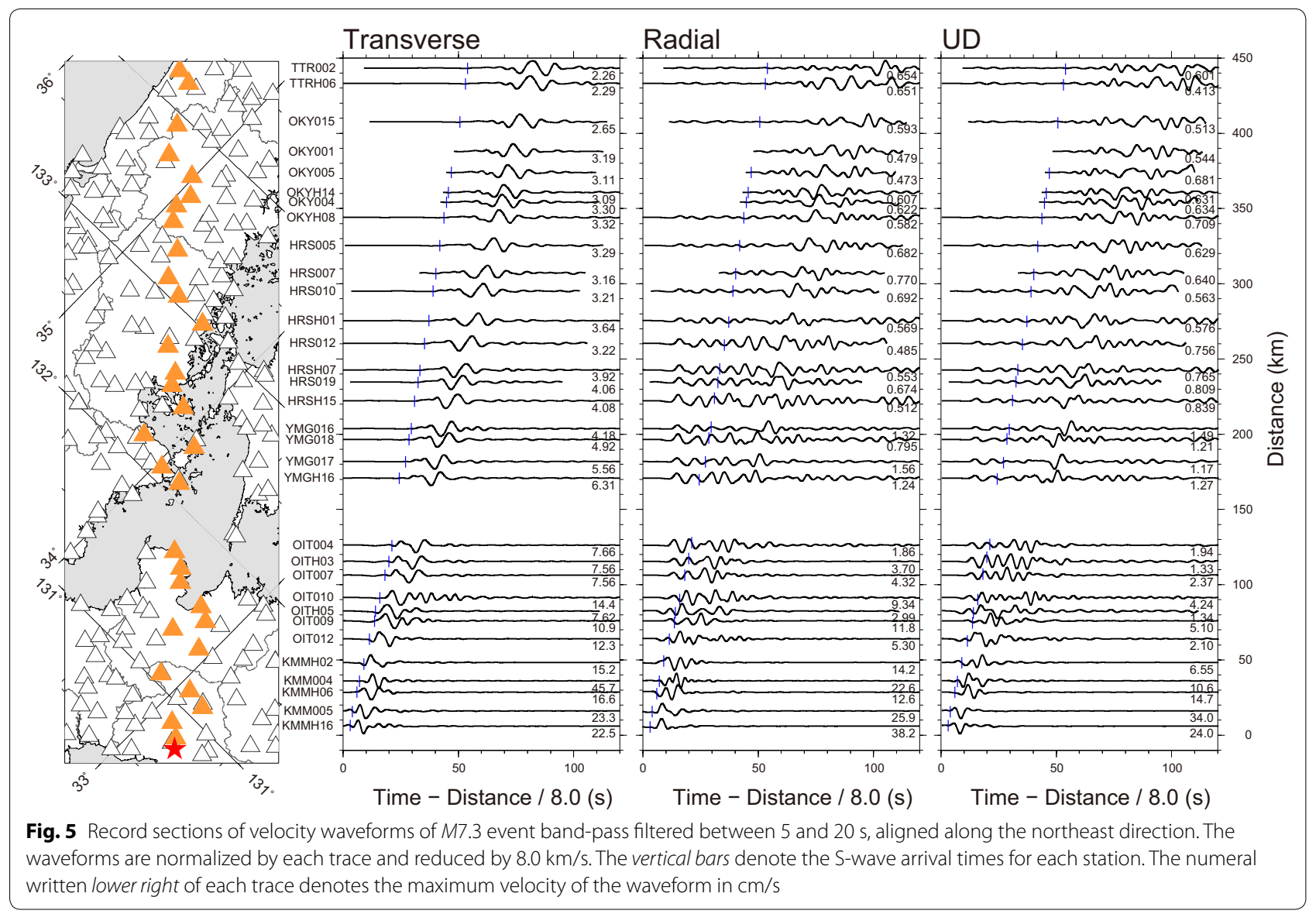

for the corresponding phase at each station and do not use the time information, such as the arrival times or whole waveforms, unlike the study by Nakamura and Aoi (2017). The used stations are selected based on the following conditions: (1) the distance from OIT009 is shorter than $200 \mathrm{~km}$ and (2) the corresponding phase is clearly identified. Using the empirical attenuation relation for crustal earthquakes proposed by Morikawa and Fujiwara (2013), which covers a wide magnitude range $\left(M_{\mathrm{W}}\right.$ 5.5-9.0), we perform predictions of PGA versus hypocentral distance for several combinations of the location and magnitude of the induced event. The hypocenter location of the combinations ranges from -20 to $20 \mathrm{~km}$ relative to OIT009 station for EW and NS directions at 2-km interval, and $M_{\mathrm{W}}$ ranges from 5.0 to 6.5 by 0.1 . Then, we select the combination that minimizes the residual between the observed and predicted PGAs. Because of the low sensitivity of this analysis to the event depth, the depth of the induced event is fixed at $8 \mathrm{~km}$, which is a typical depth of earthquakes in Oita region after M7.3 event. As a result of this analysis, the minimum residual was found when $M_{\mathrm{W}} 5.5$ induced event is horizontally set $6 \mathrm{~km}$ north and $2 \mathrm{~km}$ east of OIT009
(Fig. 7), whose location is indicated by gray cross adjacent to OIT009 in Fig. 6b. This is roughly consistent with the location of the large energy release derived from the back-projection analysis by Nakamura and Aoi (2017). Figure 7 also shows the comparison between the observations and the predicted attenuation relation from the best-fit solution, indicating that the predicted attenuation relation can generally reproduce the observations.

In addition to the estimated location of the induced earthquake, Fig. $6 \mathrm{~b}$ also shows the epicenters manually determined by NIED Hi-net for shallow events (depth $<=20 \mathrm{~km}$ ), where the black circles denote the events that occurred before M6.5 event: (January 1, 2015, to $21: 25$ April 14, 2016), the blue ones do the events that occurred between M6.5 and M7.3 events, and the red ones do the events that occurred after M7.3 event (1:24 April 16, 2016, to May 31, 2016). It has been reported that earthquakes are dynamically triggered by passage of the seismic waves (e.g., Hill and Prejean 2007) particularly in seismically active region. M7.3 event seems to have dynamically triggered the moderate-sized earthquake of $M_{\mathrm{W}} 5.5$ in the area where the seismicity existed before the Kumamoto earthquakes, and afterward the 
a
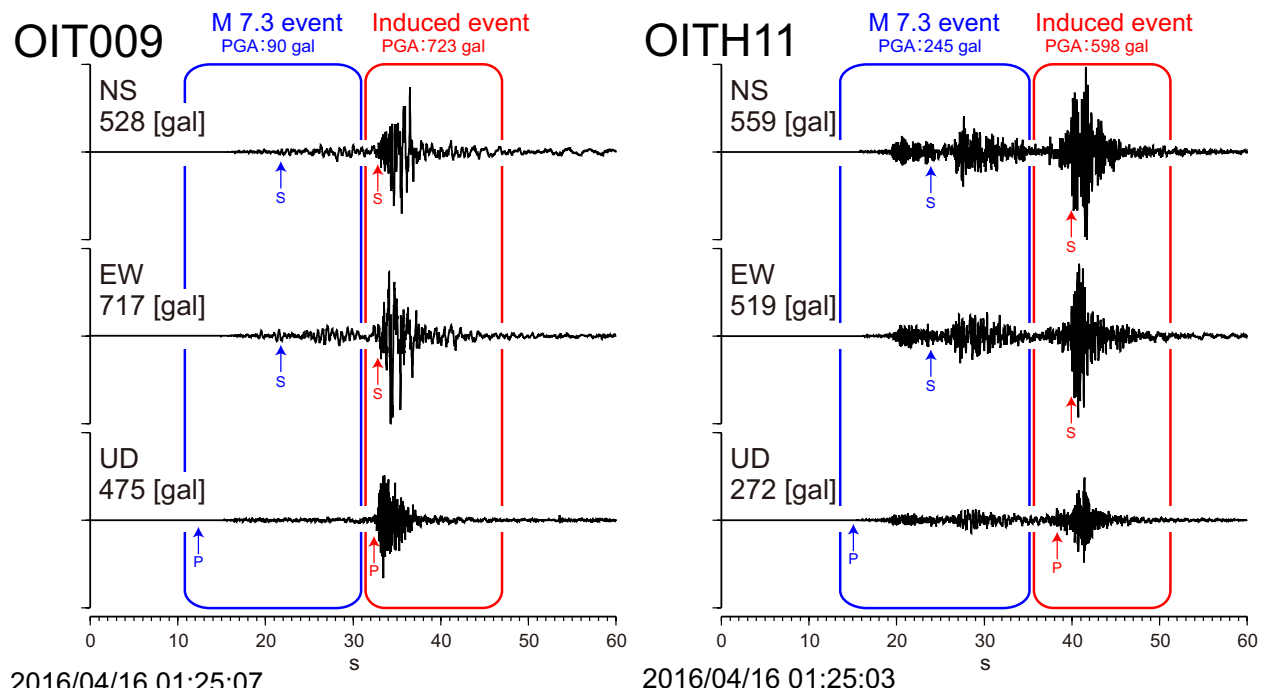

b

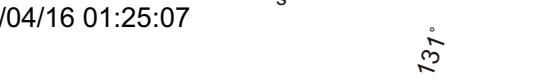

2016/04/16 01:25:03
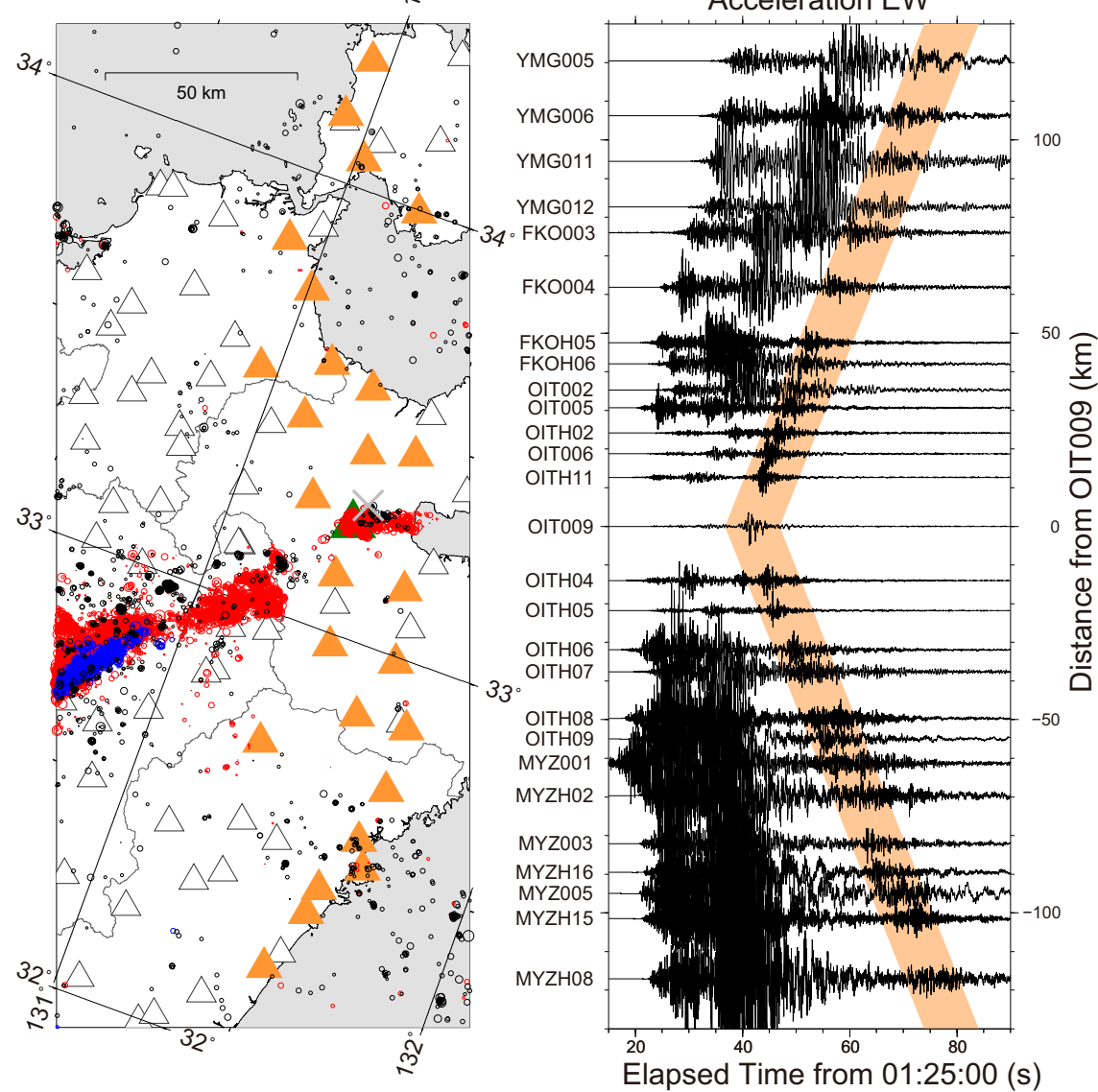

Fig. 6 a Acceleration waveforms observed at OIT009 and OITH11 which show the direct waves from M7.3 event and the wave arriving later generated by the induced earthquake near these stations. b Record section of acceleration waveforms band-pass filtered between 0.1 and $5 \mathrm{~s}$. The broad orange line corresponds to the apparent velocity of $3.5 \mathrm{~km} / \mathrm{s}$. In the map, the triangles show the stations used to plot the record section and the white cross does the location of the induced event estimated in this study. The epicenters of the shallow events determined by NIED Hi-net are also shown in the map: (black circles) the events that occurred before M6.5 event (January 1, 2015, to $21: 25$ April 14, 2016); (blue circles) the events that occurred between M6.5 and M7.3 events; (red circles) the events that occurred after M7.3 event (1:24 April 16, 2016, to May 31, 2016) 

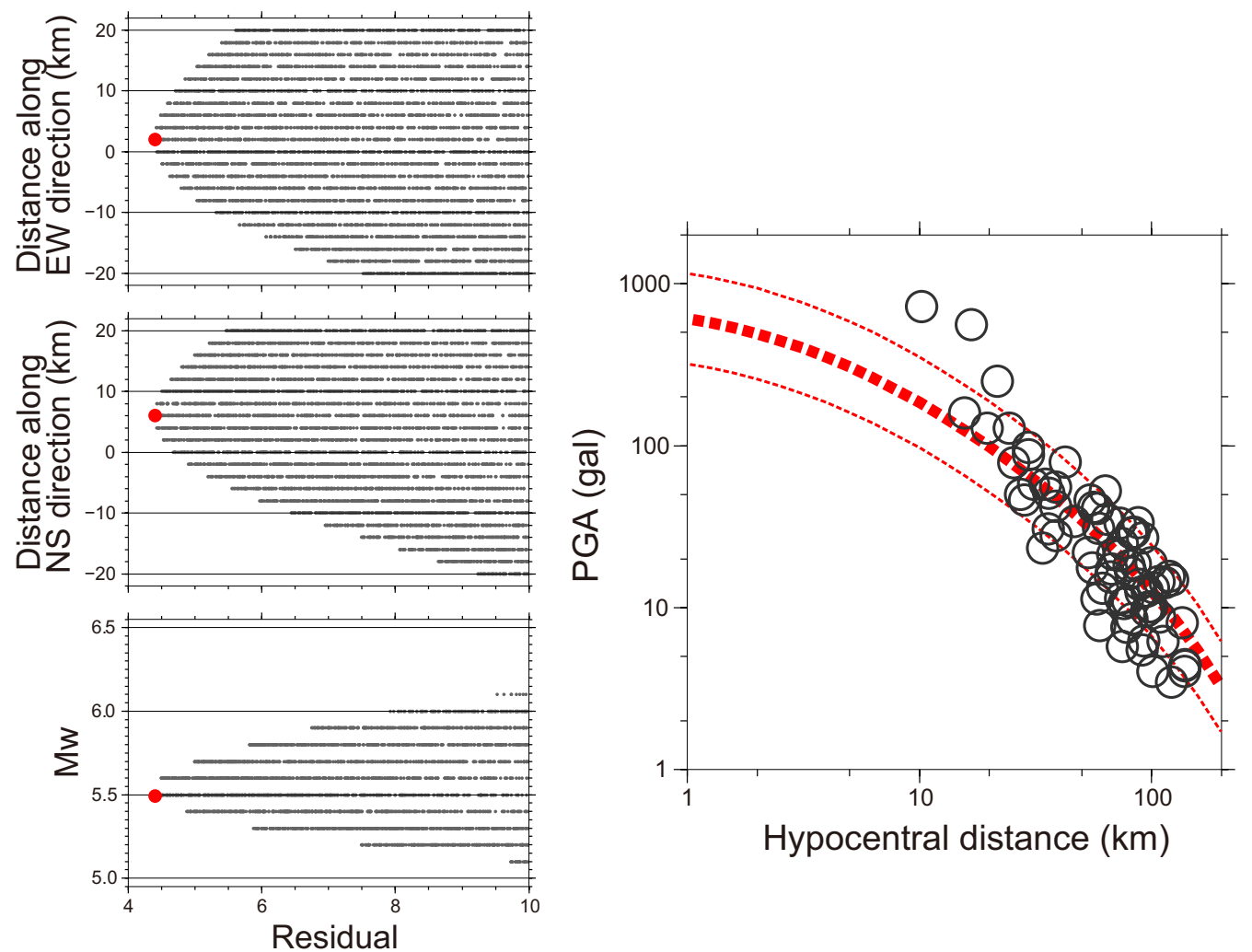

Fig. 7 Search results of the location and magnitude of the induced earthquake which give the smallest residual between the observed PGA of corresponding phase and the empirical relation by Morikawa and Fujiwara (2013). In the left panels, the values marked with red circles are the estimated distance from K-NET OIT009 station to the epicenter of the induced earthquake and the estimated moment magnitude. Right panel shows the attenuation of the observed PGA to the distance from the estimated hypocenter and the empirical relation for estimated moment magnitude denoted by the red line. Thin lines denote the range of the standard deviation of the empirical relation

seismicity increased in the wider area. There are some studies to detect triggered local events in strong-motion records (e.g., Fischer and Sammis 2009); however, it is rare that the phases of the triggered event can clearly be detected in the original non-filtered acceleration records. The Kumamoto earthquakes posed an example that a triggered event could affect the feature of strong-motion records by generating peak amplitudes.

\section{Potential of real-time strong-motion data for earthquake disaster mitigation}

We have so far elaborated on the strong-motion characteristics found from the triggered strong-motion data. The continuous observation of strong motions in real time has a great potential for mitigation of earthquake disasters and becomes feasible thanks to the advancement of information and communication technology. NIED has been conducting the real-time continuous observation trial for most of KiK-net stations and some K-NET stations. Strong-motion indexes, such as PGA,
PGV, and real-time seismic intensity (Kunugi et al. 2008, 2013), are calculated at each station in situ and are transmitted through the continuous communication line. One useful product of the trial is a Web service 'Kyoshin monitor,' which visualizes the current ground motion on the map (http://www.kmoni.bosai.go.jp/). Users can intuitively recognize the earthquake occurrence and the propagation of the seismic waves as the colors change radially from the certain area, i.e., the source area. In addition, we are making efforts to take advantage of the real-time strong-motion data to contribute to the earthquake disaster mitigation through more quantitative approach.

One example is the development of a methodology to immediately judge the region to be warned of large shakings (hereafter, warning region) based on the observed strong ground motions (Nakamura et al. 2014). Typical earthquake early warning (EEW) methods estimate the regions exposed to the large ground shakings based on the source information determined rapidly after the earthquake occurs. In our proposed methodology, 
we use the fact that the large strong motions are actually observed at near-by stations or neighboring areas. Whereas the same kind of idea is employed for a warning to a specific structure (e.g., Iervolino 2014), the proposed methodology aims to issue a warning to wider area not only to the specific site. We use the same region division to issue a warning as an area division by JMA to report a seismic intensity and to issue an EEW. A region in which the observed real-time seismic intensity exceeds the first criterion value at one station or a few stations is judged as a warning region. Then, regions adjacent to the warning region according to the former criterion and regions where the real-time seismic intensity exceeds the second criterion value are also judged as warning regions. This methodology has a possibility of more rapidly providing the warning information to the wider areas. Figure 8 shows how this methodology works for M7.3 event using K-NET and KiK-net data with the first and second criterion values of 4.5 and 3.5, respectively. $5 \mathrm{~s}$ after the earthquake occurrence, the observed ground motion exceeds the first criterion value at one station in a region indicated by red in Fig. 8a, and then, the red region and adjacent regions indicated by green, 7 regions in total, are judged as warning regions. As the ground motions spread, the number of the warning regions increases and almost whole Kyushu island is judged as warning regions $25 \mathrm{~s}$ after the origin time. Figure $8 \mathrm{~b}$ compares the number of the warning regions with the observations and the estimation of seismic intensity for K-NET and KiK-net stations using the source information and the procedure

a

$5 \mathrm{~s}$ from the origin time $20 \mathrm{~s}$ from the origin time $25 \mathrm{~s}$ from the origin time

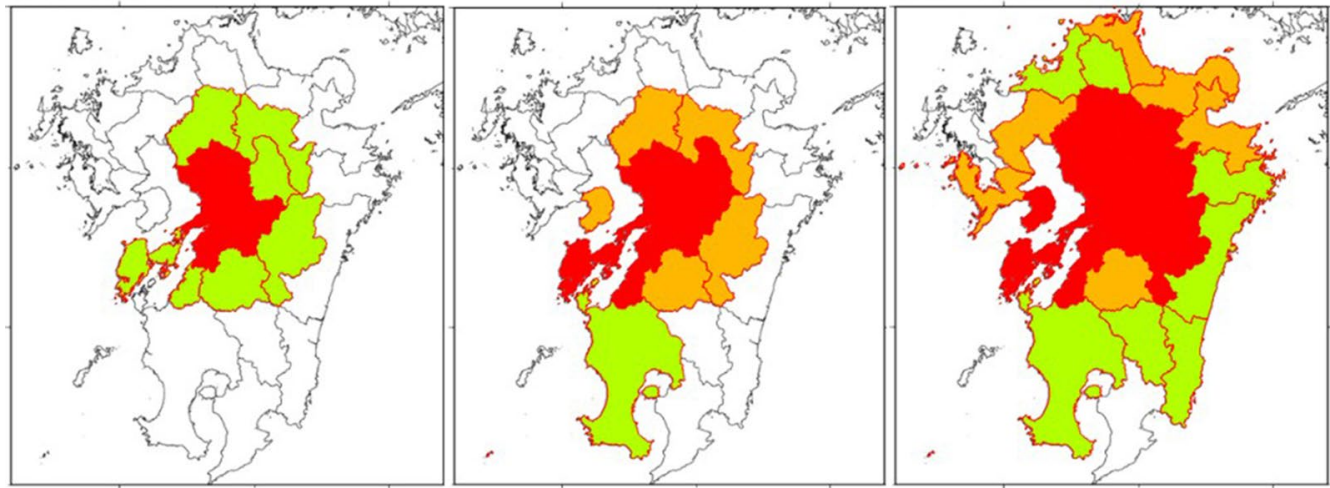

b

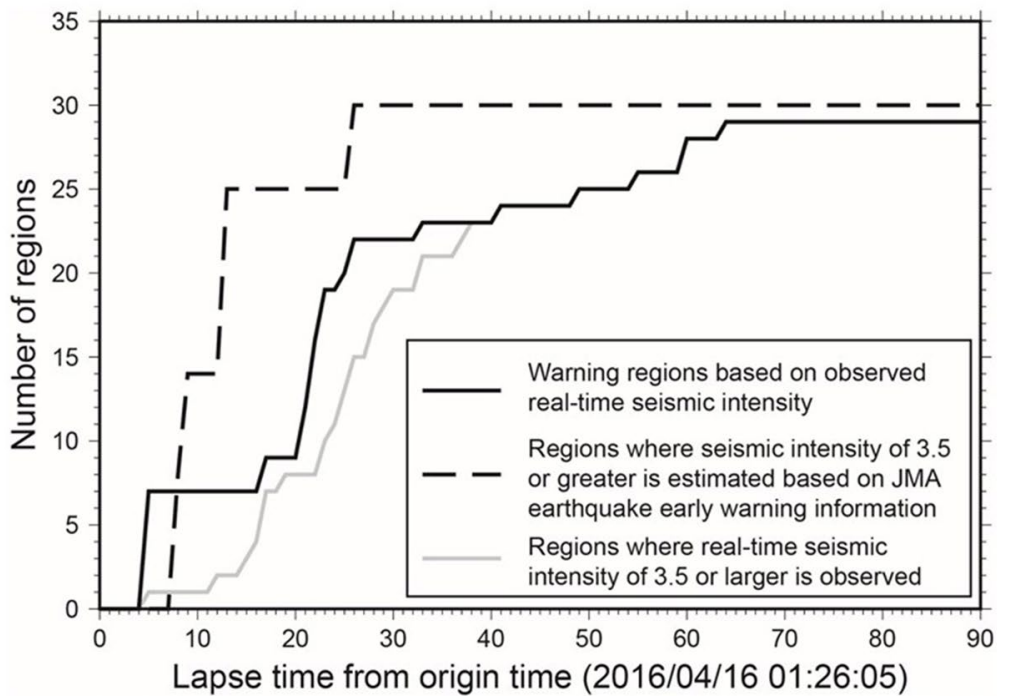

Fig. 8 a Application of the methodology to judge the warning regions based on the observed real-time seismic intensity to M7.3 event. The warning regions, colored as red, orange, and green, respectively, denote the regions where the ground motion exceeds the first criterion value, the regions where the ground motion exceeds the second criterion value, and the regions adjacent to the red regions. $\mathbf{b}$ Comparison of the numbers of the warning regions, regions where seismic intensity of 3.5 or greater is estimated based on JMA EEW information and regions where real-time seismic intensity of 3.5 or larger is observed 
of JMA EEW (e.g., Hoshiba et al. 2008). The first judgment of the warning regions is $3 \mathrm{~s}$ faster than the first estimation based on the JMA EEW information in which 8 regions would be exposed to the seismic intensity of 3.5 or greater. Afterward, the estimation based on the JMA EEW could forecast strong shakings for wider region faster. Until $38 \mathrm{~s}$, the judgment of the warning regions by our methodology is ahead of the observations. The methodology to judge the warning regions is simple but effective to quickly grasp the regions to be strongly shaken.

Like the methodology to judge the warning regions, a real-time forecast of ground motions based on the observed strong motions is considered to be fruitful making up for weak points of the typical EEWs (e.g., Kunugi et al. 2009; Hoshiba and Aoki 2015). Since the observations are spatially discrete and inhomogeneous, we develop the practical system to interpolate the strong motions in real time that is required for the real-time forecast of ground motion, as also proposed in the data assimilation approach of Hoshiba and Aoki (2015). For real-time interpolation every second for every $1 \mathrm{~km}$ mesh all over Japan, the inverse distance weighting (IDW) method shown as Eq. (1) is employed.

$$
\bar{z}=\frac{\sum_{i=1}^{N} z_{i} / r_{i}^{P}}{\sum_{i=1}^{N} 1 / r_{i}^{P}}
$$

The interpolated data $\overline{\mathrm{z}}$ are derived from the strongmotion index $z_{\mathrm{i}}$ observed at the station located at the distance $r_{i}$ from the target mesh. The observed data of $N$ neighboring stations within the certain distance are used for the interpolation and $P$ is the exponent. Using the IDW method, the real-time interpolation of current strong-motion index all over Japan becomes feasible. We show the IDW interpolation of PGA during M7.3 event as an Additional file 1: Movie A1. Here, the interpolation is conducted using $4(=N)$ neighboring stations within $50 \mathrm{~km}$ with exponent $P=2$. The interpolated data well captures the earthquake occurrence and the seismic wave propagation. In Fig. 8a, the warning regions $25 \mathrm{~s}$ after the origin time exist more in the northern Kyushu region, particularly to the northeast of the source region, than in the southern Kyushu, which is judged as warning regions afterward. This reflects that the large amplitude propagated to the northeast direction probably due to the rupture process of $M 7.3$ event, as can be also seen from Additional file 1: Movie A1, suggesting that the real-time forecast of strong ground motion can include the effect of the finite fault rupture.

\section{Conclusions}

K-NET and KiK-net have obtained a large number of strong-motion data due to the 2016 Kumamoto earthquake sequence, and NIED has opened those data to the public through the internet. They include much information useful to investigate the seismic damages as well as the nature of earthquakes. In this paper, we simply focus on the observed strong-motion characteristics of two large earthquakes, $M 6.5$ and M7.3 events, starting from the spatial distributions and the attenuation of PGA and PGV. The spatial distributions of PGA and PGV are more complex for M7.3 event than for $M 6.5$ event. The complexity is a result of the source rupture process and the induced local earthquake. Although the near-source regions are, of course, exposed to the severe shakings, PGA and PGV observed within the area where the hypocentral distance is less than $200 \mathrm{~km}$ are typical for earthquakes of that magnitude from the viewpoint of comparison with the empirical attenuation relation. Nevertheless, as the largest crustal earthquake in Japan since K-NET and KiK-net were constructed, the strong motions of M7.3 event show the notable characteristics that the longperiod large-amplitude phase efficiently propagated through western Japan and that the moderate-sized earthquake was induced at a location of approximately $70 \mathrm{~km}$ away from the epicenter, causing the large acceleration locally. In addition to these features found from the reliably recorded triggered data set, we present a potential of the real-time continuous strong-motion observation starting with 'Kyoshin monitor' and by demonstrating the methodology to judge the warning regions based on the observed real-time seismic intensity and the real-time interpolation of the strong motions using IDW method. From now on, we will continue to make efforts to reliably obtain the strong ground shakings and also to utilize those data for earthquake disaster mitigation, based on the accumulated knowledge including the 2016 Kumamoto earthquake sequence.

\section{Additional file}

Additional file 1: Movie A1. PGA distribution every one second for M7.3 event interpolated using the IDW method.

\begin{abstract}
Abbreviations
$\mathrm{AVS}_{30}$ : average S-wave velocity in the upper $30 \mathrm{~m}$; EEW: earthquake early warning; IDW: inverse distance weighting; JMA: Japan Meteorological Agency; JST: Japan Standard Time; NIED: National Research Institute for Earth Science and Disaster Resilience; PGA: peak ground acceleration; PGV: peak ground velocity; UTC: universal coordinated time.
\end{abstract}

\section{Authors' contributions}

WS, SA, TK, HK, NM, and HN designed the study, analyzed the data, and interpreted the results. WS and HK drafted the manuscript. TK and HF participated in the design of the study and interpreted the results. All authors read and approved the final manuscript.

\section{Acknowledgements}

We thank three anonymous reviewers for the helpful comments. We used the source information determined by the JMA EEW. We used the Generic Mapping Tools (Wessel and Smith 1998) to draw the figures. 


\section{Competing interests}

The authors declared that they have no competing interests.

Received: 1 August 2016 Accepted: 14 January 2017

Published online: 30 January 2017

\section{References}

Aoi S, Kunugi T, Nakamura H, Fujiwara H (2011) Deployment of new strong motion seismographs of K-NET and KiK-net. In: Akkar et al (eds) Earthquake data in engineering seismology, geotechnical, geological, and earthquake engineering 14. Springer, Berlin, pp 167-186. doi:10.1007/978-94-007-0152-6_12

Dhakal YP, Suzuki W, Kimura T, Kunugi T, Aoi S (2016) Analysis of long-period response spectra from the $2016 \mathrm{Mw} 7.1$ Kumamoto earthquake. In: Japan association for earthquake engineering annual meeting P4-20

Fire and Disaster Management Agency (2016) Earthquakes that occurred in Kumamoto region of Kumamoto prefecture, 92nd report, revised on December 28, 2016 (in Japanese). http://www.fdma.go.jp/bn/2016/ detail/960.html. Accessed 28 Dec 2016

Fischer AD, Sammis CG (2009) Dynamic driving of small shallow events during strong motion. Bull Seismol Soc Am 99:1720-1729. doi:10.1785/0120080293

Fujiwara H, Kunugi T, Adachi S, Aoi S, Morikawa N (2007) New K-NET: development of real-time system for strong-motion observation. Journal of Japan Association for Earthquake Engineering 7:2-16. doi:10.5610/jaee.7.2_2 (in Japanese with English abstract)

Fukuyama E, Suzuki W (2016) Near-fault deformation and Dc" during the 2016 Mw7.1 Kumamoto earthquake. Earth Planets Space 68:194. doi:10.1186/ s40623-016-0570-6

Furumura T, Kennett BLN, Koketsu K (2003) Visualization of 3D wave propagation from the 2000 Tottori-ken Seibu, Japan, Earthquake: observation and numerical simulation. Bull Seismol Soc Am 93:870-881. doi:10.1785/0120020160

Headquarters for Earthquake Research Promotion (2013) Long-term evaluation of the active faults in Kyushu district (in Japanese). http://www.jishin. go.jp/evaluation/long_term_evaluation/regional_evaluation/kyushudetail/. Accessed 29 Jul 2016

Hill DP, Prejean SG (2007) Dynamic triggering. In: Kanamori (ed) Earthquake Seismology, Treatise on Geophysics 4. Elsevier, New York, pp 257-291

Honda R, Aoi S, Morikawa N, Sekiguchi H, Kunugi T, Fujiwara H (2004) Ground motion and rupture process of the 2003 Tokachi-oki earthquake obtained from strong motion data of K-NET and KiK-net. Earth Planets Space 56:317-322. doi:10.1186/BF03353058
Hoshiba M, Aoki S (2015) Numerical shake prediction for earthquake early warning: data assimilation, real-time shake mapping, and simulation of wave propagation. Bull Seismol Soc Am 105:1324-1338. doi:10.1785/0120140280

Hoshiba M, Kamigaichi O, Saito M, Tsukada S, Hamada N (2008) Earthquake early warning starts nationwide in Japan. EOS Trans AGU 89:73-74. doi:10.1029/2008EO080001

lervolino I (2014) Engineering earthquake early warning via regional networks. In: Zschau W (ed) Early warning for geological disasters, advanced technologies in earth sciences. Springer, Berlin, pp 333-351

Kinoshita S (1998) Kyoshin Net (K-NET). Seismol Res Lett 69:309-332

Kubo H, Suzuki W, Aoi S, Sekiguchi H (2016) Source rupture processes of the 2016 Kumamoto, Japan, earthquakes estimated from strong motion waveforms. Earth Planets Space 68:161. doi:10.1186/s40623-016-0536-8

Kunugi T, Aoi S, Nakamura H, Fujiwara H, Morikawa N (2008) A Real-Time Processing of Seismic Intensity. Zisin 60:243-252. doi:10.4294/zisin.60.243 (in Japanese with English abstract)

Kunugi T, Aoi S, Fujiwara H (2009) Strong-motion observation in Japan — History and Perspective-. Zisin 61:S19-S34. doi:10.4294/zisin.61.19 (in Japanese with English abstract)

Kunugi T, Aoi S, Nakamura H, Suzuki W, Morikawa N, Fujiwara H (2013) An improved approximating filter for real-time calculation of seismic intensity. Zisin 65:223-230. doi:10.4294/zisin.65.223 (in Japanese with English abstract)

Midorikawa S, Matsuoka M, Sakugawa K (1994) Site Effects on Strong Motion Records during the 1987 Chiba-ken-toho-oki, Japan Earthquake. The 9th Japan Earthquake Engineering Symposium vol 3, pp 85-90

Morikawa N, Fujiwara H (2013) A new ground motion prediction equation for Japan applicable up to M9 Mega-Earthquake. J Disaster Res 8:878-885

Nakamura T, Aoi S (2017) Source location and mechanism analysis of an earthquake triggered by the 2016 Kumamoto, southwestern Japan, earthquake. Earth Planets Space 69:6. doi:10.1186/s40623-016-0588-9

Nakamura H, Kunugi T, Suzuki W, Aoi S (2014) Development of area early warning method using real-time seismic intensity. Seismol Soc Jpn Fall Meet 2014:B11-04 (in Japanese)

NIED (2016) Moment tensors by the NIED F-net. http://www.hinet.bosai.go.jp/topics/nw-kumamoto160416/?LANG=en\&m=mecha. Accessed 30 Jul 2016

Okada Y, Kasahara K, Hori S, Obara K, Sekiguchi S, Fujiwara H, Yamamoto A (2004) Recent progress of seismic observation networks in Japan -Hi-net, F-net K-NET and KiK-net-. Earth Planets Space 56:xv-xxviii. doi:10.1186/BF03353076

Si H, Midorikawa S (1999) New attenuation relationships for peak ground acceleration and velocity considering effects of fault type and site condition. J Struct Constr Eng AlJ 523:63-70 (in Japanese with English Abstract)

Wessel P, Smith WHF (1998) New, improved version of Generic Mapping Tools released. EOS Trans Am geophys Un 79:579

\section{Submit your manuscript to a SpringerOpen ${ }^{\circ}$ journal and benefit from:}

- Convenient online submission

- Rigorous peer review

- Immediate publication on acceptance

- Open access: articles freely available online

- High visibility within the field

- Retaining the copyright to your article

Submit your next manuscript at $>$ springeropen.com 